\title{
Standards in neurological rehabilitation, June 1997
}

\author{
European Federation of Neurological Societies Task Force
}

\author{
Correspondence to: Michael P. Barnes, Hunters Moor Rehabilitation Centre, Hunters Road, \\ Newcastle Upon Tyne NE2 4NR, UK
}

The European Federation of Neurological Societies (EFNS) Scientific Panel on Neurorehabilitation established a Task Force on standards in neurological rehabilitation in June 1996. The remit for the Task Force was to: (1) produce a report on the state of neurological rehabilitation across Europe; and (2) recommend standards for the provision of neurological services for disabled people. The main conclusions of the Task Force were as follows:

(1) A questionnaire circulated to each European member country has indicated a significant lack of adequate neurological rehabilitation facilities across Europe. Very few countries have any established network of neurological rehabilitation centres. Few countries have adequately trained neurological rehabilitation physicians, therapists or nurses. Such poor facilities should be seen in the context of the large numbers and increasing prevalence of people with neurological disabilities.

(2) The Task Force has summarized the significant benefits that can follow from the establishment of a dedicated and cost effective neurological rehabilitation service including functional improvement, reduction of unnecessary complications, better coordination and use of limited resources, improved opportunities for education, training and research and a clear point of contact for the disabled person.

(3) The Task Force recommends minimum standards for the prevention of neurological disability including access to health education, genetic counselling and emergency resources. The Task Force also encourages governments to invest in improved legislation for accident prevention.

(4) The Task Force has outlined some minimum standards for the staffing of a neurological rehabilitation service including improved training both for neurologists and rehabilitation physicians. Such training could include a cross-national training programme both for physicians and other health care staff.

(5) The Task Force supports a two-tier system of neurological services. We believe that disabled individuals should have access to a regional specialist service as well as a local community service. The regional specialist service would cater for people with more complicated and severe disabilities, including spinal injury and severe brain injury. The regional centres would provide specialist expertise for wheelchairs and special seating, orthotics, continence and urological services, aids and equipment including communication aids and environmental controls, prosthetics and driving assessment. The Task Force additionally endorses the development of local and community based rehabilitation teams with clear links to the regional centre.

(6) The Task Force recognizes the limited amount of rehabilitation research and encourages individuals, universities and governments to invest more in rehabilitation research. Such investment should produce benefits for disabled people and their carers and in the long term benefits for the national economy.

(7) The Task Force realizes that neurological rehabilitation is poorly developed both in Europe and the world as a whole. We firmly endorse international co-operation in this field and are happy to co-operate with any international organization in order to develop such links for clinical, educational or research initiatives.

(8) The Task Force encourages individual countries to produce a document summarizing their own situation with regard to these standards and to produce a timetable for action to improve their situation. The EFNS Task Force would be pleased to assist in the publication of such deliberations or to act as a focus for international education and research or for sharing of examples of good practice.

\section{BACKGROUND}

The European Federation of Neurological Societies (EFNS) Task Force on Standards in Neurological Rehabilitation was established in June 1996. The remit for the Task Force was to produce a report on the state of neurological rehabilitation across Europe and to recommend standards for the provision of neurological rehabilitation services for disabled people. Members of the Task Force were:

- Michael P. Barnes, University of Newcastle upon Tyne, UK (Chair)

- Franz Gerstenbrand, Vienna, Austria

- Nils Erik Gilhus, University of Bergen, Norway
- Milan Gregoric, Institute for Rehabilitation of the Republic of Slovenia, Slovenia

- Eline Lindeman, University Hospital Utrecht, The Netherlands

- Karl Heinz Mauritz, Klinik Berlin, Berlin, Germany

- Leopold Saltuari, University Hospital of Neurology, Innsbruck, Austria

- Jana Sussova, Charles University, Prague, Czech Republic

- Anthony Ward, North Staffordshire Rehabilitation Unit, Stoke on Trent, UK 
The Task Force is aware that there are great difficulties in suggesting standards for neurological rehabilitation across the whole of Europe. The resources available for people with neurological disabilities vary widely from country to country. Some European countries have economic difficulties which means that some of our suggestions will not be achievable in the foreseeable future. Countries also vary considerably in the numbers of doctors and therapists available and in their training. However, the Task Force considers that the standards outlined in this document are desirable and realistic. Many of the suggestions could be implemented without significant resource implications. Other standards require investment and these should be seen as long-term goals and aspirations for those countries with significant economic problems.

The Task Force members will be delighted to offer advice or assistance to any country when working towards implementation of these standards.

\section{EPIDEMIOLOGY}

The Task Force is aware that the incidence and prevalence of disabling neurological disorders do vary from country to country. Multiple sclerosis, for example, is much more common in the northern part of Europe. However, there are no accurate epidemiological figures for numbers of people with disabling neurological problems in Europe as a whole. Table 1 gives the incidence and prevalence of disabling disorders per 100,000 population and is based on the best available estimates (Wade, 1987; British Society of Rehabilitation Medicine, 1993).

TABLE 1. Incidence and prevalence of some disabling neurological disorders per 100000 population

\begin{tabular}{lccc}
\hline Disease name & $\begin{array}{c}\text { Incidence } \\
\text { (people/year) }\end{array}$ & \multicolumn{2}{c}{ Prevalence } \\
\cline { 3 - 4 } & & Total & Disabled \\
\hline Parkinson's disease & 20 & 180 & 72 \\
Multiple sclerosis & 4 & 100 & 50 \\
Epilepsy & 70 & 1560 & 520 \\
Stroke & 220 & 600 & 360 \\
Head injury & 1330 & $?$ & 150 \\
Spinal injury & 2 & 60 & 50 \\
Cerebral tumour & 16 & 45 & 16 \\
Subarachnoid haemorrhage & 15 & 50 & $?$ \\
Motor neurone disease & 2 & 6 & 6 \\
Cerebral palsy & 200 & $?$ & 200 \\
& & & (school age) \\
Muscular dystrophy & 20 & 90 & $?$ \\
Polyneuropathy & 100 & $?$ & $?$ \\
Meningitis (bacterial \& viral) & 70 & $?$ & $?$ \\
\hline
\end{tabular}

Overall, it is clear that there are considerable numbers of significantly disabled individuals with a wide variety of neurological conditions. It is likely that the prevalence is increasing with improvements in acute and intensive care facilities and in the variety of treatments for such conditions as stroke and multiple sclerosis that seem to improve survival. The ageing population of Europe is a further factor that is certainly increasing the prevalence of a variety of age related conditions, particularly stroke and Parkinson's disease.

\section{PRESENT SITUATION: EFNS QUESTIONNAIRE}

The Task Force circulated a detailed questionnaire on neurological rehabilitation services to each member country. A total of 18 countries returned the questionnaire, which has enabled us to assess the state of neurological rehabilitation services across Europe in some detail.

\section{Replies}

Replies to the questionnaire were received from the following countries: Albania, Austria, Belgium, Czech Republic, Denmark, Finland, France, Germany, Italy, Norway, Portugal, Russia, Slovak Republic, Slovenia, Sweden, Switzerland, the Netherlands and the United Kingdom.

\section{Epidemiology?}

Just five countries (29\%) have any epidemiological statistics available for the numbers of neurological disabled people.

\section{Established networks of neurological rehabilitation} centres?

Six countries (35\%) had some form of network of neurological rehabilitation centres. Two countries (Slovenia and Czech Republic) have a single neurological rehabilitation centre servicing the country as a whole. Eight (47\%) countries have at least some specialists trained in neurological rehabilitation but their numbers are assessed as inadequate.

\section{Written training requirements for neurological rehabilitation physicians?}

Eight countries had written training requirements for neurological rehabilitation physicians although there were so few physicians in this field that much training had to be carried out on an ad hoc basis and there were often insufficient numbers to merit proper training programmes.

\section{Therapy support}

About half of the respondents felt their country did have reasonable numbers of appropriately trained therapists to support a neurological rehabilitation team. However, the great majority of these respondents also felt these individuals were not coherently organized into such teams nor were there adequate training facilities for therapists who wished to specialize in this area. 


\section{Community care}

Only seven countries felt there was any significant community rehabilitation service available. Community neurological rehabilitation in most countries is either not organized at all or is organized through specialist regional centres.

\section{Minimum written standards of care for neurological disabled people?}

Four countries had written standards of care for people with neurological disabilities.

\section{Summary}

This survey does regrettably confirm that neurological rehabilitation services are generally inadequate across Europe. No country in this survey felt it had adequate facilities either in specialist centres or at a community level. There are inadequate numbers of physicians trained in neurological rehabilitation and, although some countries report sufficient numbers of therapists, their training seems to be suboptimal and the organization of trained staff into coherent rehabilitation teams is very patchy. There is clearly room for significant improvement and an urgent need for further investment of resources into facilities, staff and training.

\section{PRINCIPLES OF NEUROLOGICAL REHABILITATION}

Rehabilitation has been defined as: an active process by which those disabled by injury or disease achieve a full recovery or if a full recovery is not possible realise their optimal physical, mental and social potential and are integrated into their most appropriate environment.

(World Health Organization, 1980)

Rehabilitation does differ from many medical specialities in that it is an active process of education and enablement. It is focused on the proper management of disability and the minimization of handicap and less focused on the problems of diagnosis and impairment. Thus, neurological rehabilitation is a speciality that requires both neurological skills and training as well as training in the complementary skills of rehabilitation medicine. It is a process that requires understanding and knowledge about the value and importance of other therapies and nursing, and empathy and understanding of the problems of disability and of caring for someone with a disabling condition.

In the United Kingdom the Prince of Wales Advisory Group on Disability (1985) has produced some service values that should underpin any neurological rehabilitation service. The Task Force endorses these values:

- Choice as to where to live and how to maintain independence without overprotection or the risk of unnecessary hazards, including help in learning how to choose

- Consultation with disabled people and their families on services as they are planned
- Information clearly presented and readily available to the most severely disabled consumers

- Participation in the life of local and national communities in respect to both responsibilities and benefits

- Recognition that long-term disability is not synonymous with illness and that the medical model of care is inappropriate in the majority of cases

- Autonomy: freedom to make decisions regarding the way of life best suited to an individual disabled person's circumstances

The underlying principle is therefore that disabled people, and their carers, should be intrinsically involved in the rehabilitation process. It is a process that should be carried out by or with disabled people and not to or for disabled people.

Rehabilitation should be seen as a process which facilitates the full participation of disabled people in society. The Task Force endorses the recently published UN Standard Rules for Persons with Disabilities (United Nations, 1996) which emphasized the need for equal rights and equal participation of disabled people in society.

\section{WHY HAVE A NEUROLOGICAL REHABILITATION SERVICE?}

There are significant benefits from a dedicated neurological rehabilitation service.

\section{Functional benefit}

There is now considerable evidence that the rehabilitation process does produce real functional benefit and improved outcomes for disabled people (Cope and Hall, 1982; Heinemann et al., 1989; Dennis and Langhorne, 1994).

\section{Reduction of unnecessary complications}

Many problems with disability are caused by unnecessary complications. Poorly managed spasticity can result in contractures and thus unnecessary further restriction on mobility or use of arms. Pressure sores are nearly always preventable but if allowed to develop can cause pain, infection, increasing disability and often require expensive hospital admission and surgery. A neurological rehabilitation team can assure proper attention is paid to nutrition and the assessment and management of swallowing disorders. Many behavioural disorders, common after head injury, are amenable to psychological intervention. Anxiety, depression and other emotional problems often accompany physical disability and are amenable to appropriate intervention.

\section{Co-ordination and use of resources}

A neurological rehabilitation team can provide a better coordinated service for the disabled person and family. This should lead to a better use of limited resources and prevention of duplication of assessment and treatment. 
Reduction of crisis admission to hospital

A properly planned, goal-orientated rehabilitation service should offer adequate long-term support to the disabled person and carer in order to prevent inappropriate crisis or other residential admission.

\section{Lessened handicap}

Maximum improvements in independence and quality of life should lead to better chances of employment (Wehman et al., 1993). Social and leisure opportunities should be increased and overall rehabilitation will maximize the chances of the disabled person leading a full and active life and making a significant contribution to the local community.

\section{Cost effective}

An efficient rehabilitation process should allow a shorter assessment time, less duplication and a more accurate needs assessment, leading to improved effectiveness of service provision and, in the long term, cost savings.

\section{Education and teaching}

A neurological rehabilitation team should act as a focus for education and teaching of medical, nursing and therapy colleagues. This improvement in knowledge will further ease the problems that disabled people face when in contact with health services.

\section{Research}

There is a considerable need for research in many aspects of neurological rehabilitation, particularly applied research into the best methods of service delivery and reduction of disability. A co-ordinated neurological rehabilitation team should act as a base for such research projects.

\section{Point of contact}

Although a complicated array of services are necessary for the disabled person, there is often poor co-ordination between different government departments. A neurological rehabilitation team can act as a point of contact for information and advice for the disabled person and family, and ease the path through health and social systems.

\section{MINIMUM STANDARDS FOR NEUROLOGICAL REHABILITATION}

\section{Prevention}

Many neurological conditions cannot be foreseen or prevented. However, the Task Force recommends that where prevention is possible health services should be available to offer appropriate health education and advice. Health care professionals should be available in order to promote personal health care, including education about areas of risk which can result in neurological damage. Smoking, obesity, lack of exercise, hypertension and alcohol and drug abuse are all potentially preventable risk factors in relation to neurological disability.

The Task Force recommends that each country should have access to a genetic counselling service.

It also recommends that each country should have a national campaign aimed at the promotion of accident prevention. This should include legislation enforcing the wearing of seat-belts, safety helmets, improve road conditions and appropriate sports regulations as well as regulations for workers in dangerous environments. The incidence of head and spinal injury can be reduced by such measures (Barnes, 1996).

The Task Force is also aware that later disability can be limited by fast emergency response and initiation of appropriate treatment for conditions such as head injury, spinal cord injury, stroke and subarachnoid haemorrhage. Every individual should have quick access to such emergency care.

\section{Staffing}

The Task Force recommends that every person with a neurological disability should have access to support and advice from a physician expert in neurological rehabilitation. The number of these experts in any country will clearly depend on the design and scope of rehabilitation and neurological facilities and services. However, as a general rule, most countries with an established network of these physicians find that one or two physicians per 250000 population is sufficient to provide reasonably quick and efficient access for the disabled population.

In some countries these specialists will have a neurological background and training while in other countries rehabilitation services are provided from the separate speciality of rehabilitation or physical medicine. The Task Force believes that dual training in both fields is important and encourages medical authorities in European countries to support and promote a comprehensive programme of training in neurology and rehabilitation medicine. If single-speciality training is the only possible option then the Task Force believes it is important for neurologists to have a period of exposure and training in rehabilitation medicine or for rehabilitation physicians to have a period of exposure and training in acute and diagnostic neurology. In some countries such training programmes may be difficult to fund or establish: the EFNS Task Force wishes to promote the idea of crossnational training programmes and endorses the move towards a European standard for such training programmes.

The Task Force also endorses the idea of established neurologists or rehabilitation physicians training in the other speciality. Thus, we also support the concept of cross-national courses in neurological rehabilitation, designed for established physicians. The Task Force is not aware of any such courses available at the present time.

The Task Force, being a medical group, does not wish to dictate standards for other professional disciplines. However, 
we do firmly endorse the view that every neurologically disabled person should have access to a full multidisciplinary team trained in the management of neurological disabilities. The composition of such a team will clearly vary from country to country but we consider the minimum discipline requirements for a comprehensive team are:

- physiotherapy

- occupational therapy

- access to speech and language therapy

- access to clinical neuropsychology

- rehabilitation nursing

- occasional and intermittent access to other relevant disciplines such as chiropody (podiatry), dietetics, social work and to other medical disciplines including orthopaedics, urology, plastic surgery, etc, as required.

The Task Force formally endorses the view that the best outcomes can be achieved through a rehabilitation team. This implies multidisciplinary or interdisciplinary working and a client centred goal setting process. Such methods also imply a blurring of strict professional boundaries with proper team co-ordination.

It is clear from our questionnaire that although therapy and nursing resources exist in all countries these individuals are generally not moulded into coherent disability teams. Thus, it is likely that there is considerable unnecessary duplication and overlap of scarce resources.

\section{Services}

The Task Force believes that the most efficient outcomes will be obtained by a two-tier system of neurological service delivery. Individuals should have access to regional specialist expertise, particularly for the management of the most complex and severe disabilities. However, most disability can be managed at a local community level and most disabled people will not need access to regional services. Thus, we strongly encourage the development of more locally orientated neurological disability teams either working from local hospitals or working directly in the community.

\section{Regional}

The Task Force believes that regional neurological rehabilitation centres are required in order to provide access to specialist experts familiar with the management of complex and severe disabilities. It is likely that such regional centres will also act as a focus for education, training and research and they should be linked to university teaching centres. They must be staffed by adequate numbers of physicians trained in neurological rehabilitation with the support and co-operation of specialist therapists and nurses. The numbers of such regional centres in each country will depend on available resources, geography and the general organization of the health system.

The services delivered from such regional centres will also vary from country to country depending on available staff and resources. However, the following services are those more likely to be provided at a regional rather than local level:

\section{Spinal injuries}

The incidence of spinal injuries, at least in countries not affected by war, is relatively low and it is unlikely that sufficient expertise will be available at a local community level. The Task Force endorses the development of regional spinal injuries centres, preferably based within the context of a regional neurological, neurosurgical or rehabilitation centre.

\section{Severe brain injury}

Individuals with severe trauma to the central nervous system often have a very complicated range of physical, psychological and social problems as well as damage to other organ systems. This is particularly true for individuals who develop severe neurobehavioural problems following a brain injury. Specialist expertise in neuropsychiatry or neuropsychology is often inadequate and only likely to be available at a regional or supraregional level.

\section{Wheelchairs and special seating}

Most aspects of standard wheelchair assessment and provision should be provided locally. However, people with more complicated disabilities often require special seating with the consequent input from specialist physicians, therapists and orthotists.

\section{Orthotics}

Simple and common orthotic appliances should also be available locally but specialist orthotic devices for complicated disabilities will need specialist medical, physiotherapy and orthotic staff and thus should be available at a regional level.

\section{Continence and urological services}

Some individuals with difficult or complicated urological problems will need access to specialist urological services in order to prevent unnecessary complications of urinary infection and renal failure.

\section{Orthopaedic and plastic surgery}

Specialist surgical support is often required for the management of complex orthopaedic problems and pressure sores.

\section{Aids and equipment}

To maximize function, disabled people may need a variety of aids and equipment. In countries with poor health resources it is very unlikely that an appropriate range of such equipment for demonstration and assessment will be available locally. Although attempts should be made to provide a small demonstration centre for common and every day disability equipment locally. A comprehensive range of such equipment should be available on a regional basis.

\section{Communication aids and environmental controls}

Severely disabled people, particularly those with additional communication problems, should have access to both environmental control and communication aid equipment. Often 
such equipment will enable these individuals to stay at home. Specialist speech therapists and medical expertise are a prerequirement for the proper assessment of such people.

\section{Rehabilitation engineering}

A rehabilitation engineer will provide invaluable input for the assessment and development of specialist wheelchairs, seating systems, complex orthotics, prosthetics and other rehabilitation equipment. Each regional centre should have access to such a service.

\section{Prosthetics}

In most countries there are insufficient numbers of amputees to merit a local service. Obviously this may not be the case in some countries affected by a war situation. However, it is likely that necessary prosthetists and consultants with a specialist interest in this area will only be available at a regional level.

\section{Driving assessment centre}

Access to a motor vehicle is an important consideration in remaining independent. Many disabilities can now be accommodated by vehicle adaptations and the Task Force believes that disabled individuals should have access to a specialist driving assessment centre which, in turn, will probably require a specially trained therapist and driving instructor.

\section{Local and community}

The Task Force recommends that most disability services can and should be provided locally. We believe that the most costefficient way of providing such services is through a multidisciplinary neurological disability team with the core involvement of a neurological rehabilitation physician, physiotherapist, occupational therapist and nurses. Part-time involvement of other key therapists (e.g. speech and language therapist, clinical psychologist) might be available as an outreach service from the regional centre or locally shared with other appropriate disciplines. This local team will be responsible for the rehabilitation of individuals with more common disabilities, particularly those with stroke, moderate head injury, cerebral palsy, multiple sclerosis, Parkinson's disease, epilepsy and a variety of other neurological disorders. We believe that the teams must work on an interdisciplinary basis and that resources across Europe are likely to be inadequate for a rigid discipline working with consequent overlap and duplication of assessments and treatments. Most of these teams will probably be based in a local hospital for the sake of convenience, but we firmly encourage the teams to develop community outreach into local clinics, health centres and individual homes. We are aware that the economic situation in many European countries will not allow the development of teams that are staffed only by qualified therapists or doctors. Thus, we encourage such countries to give serious consideration to the Community-Based Rehabilitation (CBR) model developed by the World Health Organization. This model allows local communities to deliver their own support mechanisms for disabled people, often with a locally trained worker supervised by qualified staff but providing basic rehabilitation, treatment and advice within the local community (Helander et al., 1989).

The Task Force recognises that this document is mainly focused on health rehabilitation. However, we also recognise that the needs of disabled people can go beyond the boundaries of health. Local disability teams have to work together with other relevant local services, particularly social services, housing and employment agencies. This would enable a more comprehensive disability service to be provided for all disabled people.

\section{Education and training}

The Task Force is aware that the standards of education and training in neurological rehabilitation are generally inadequate. There are very few countries with a co-ordinated training programme for physicians in this field and even fewer training programmes for therapists and nurses. We believe that regional centres should act as a focus for education and training programmes within each country and also be part of an inter-European network. The move towards standardization of training through the European Union is to be encouraged. The Task Force also encourages regional centres to act as a focus for education and training of other health professional colleagues. Many problems for disabled people arise when they have contact with other health services who have minimal understanding of the problems of disability.

Training programmes for disabled people and carers in proper disability self-management are also important, both for the development of self esteem and to make best use of scarce resources. This is an important task for local and regional centres.

\section{Research}

There is inadequate evidence on which to base proper rehabilitation decisions regarding the best method of service delivery, the best type of intervention and the best means of management of various disabilities. We encourage all regional centres to develop research programmes. We also encourage universities to be more active in the establishment of academic centres of rehabilitation. We recommend that European governments invest more health research money into this important field. Research into rehabilitation and neurological disability will not only produce benefits for the disabled people and their carers but in the long term should produce benefits for the national economy.

\section{International co-operation}

Neurological rehabilitation is insufficiently developed across Europe and indeed across the world as a whole. There is much to be gained by international co-operation in sharing models of good practice and education and research initiatives. We believe that international co-operation in this developing field 
is vital and that the EFNS Task Force should co-operate with other similar European and global bodies such as the European Board of Physical Medicine and Rehabilitation, the European Society for Research in Rehabilitation, the World Forum of Neurological Rehabilitation and other international and national rehabilitation and neurological bodies. The Task Force is pleased to co-operate with any similar international organization in order to develop international clinical, educational or research initiatives.

\section{TIMETABLE FOR ACTION}

Some of our suggestions, particularly with regard to multidisciplinary working, can be initiated without new resource implications. We encourage health professionals to work together in all European countries in order to assess their own standards against these guidelines and to make proposals for improvements in their working practices. We also encourage governments to invest more in this field. We are aware that for some countries not all standards will be achievable in the foreseeable future due to local economic restraints. However, these standards should definitely be the aim for all European countries.

The Task Force suggests that the next step is for individual countries to produce a document that summarizes their own situation with regard to these standards and to produce a timetable and action plan for improvement.

The EFNS Task Force will be pleased to publish the results of such deliberations or act as a focus for international education and research or the sharing of the examples of good practice.

\section{CONCLUSIONS}

The EFNS Scientific Panel has identified major shortfalls in the provision of neurological rehabilitation services. We have suggested minimum standards for such services. Many, but not all, of these standards will require further investment. We encourage professional bodies, health services and governments to give serious consideration to more investment in this field. Such investment will bring significant benefits to neurologically disabled people and their carers which in turn will bring benefits to society as a whole.

\section{REFERENCES}

Barnes MP (1996) Legislative and policy factors. In: Brain Injury and After: Towards Improved Outcome. (Ed Rose FD, Johnson DA) Wiley and Sons, New York.

British Society of Rehabilitation Medicine (1993) Advice to Purchasers: Setting NHS Contracts for Rehabilitation Medicine. British Society of Rehabilitation Medicine, London.

Cope DN and Hall KL (1982) Head injury rehabilitation: benefit of early intervention. Archives of Physical Medicine and Rehabilitation, 63, 433-437.

Dennis M and Langhorne P (1994) Stroke units save lives: where do we go from here. British Medical Journal, 309, 1273-1277.

Heinemann AW, Yarkony GM, Roth EJ, Lovell L, Hamilton B, Ginsburg K et al. (1989) Functional outcome following spinal cord injury. Archives of Neurology, 46, 1098-1102.

Helander E, Mendis P, Nelson G and Goerdt A (1989) Training in the Community For People With Disabilities. WHO, Geneva.

Prince of Wales Advisory Group on Disability (1985) Living Options: Guide-lines For Those Planning For Services For People With Severe Disabilities. Prince of Wales Advisory Group on Disability, London.

United Nations (1996) Standard Rules For Equalisation of Opportunities For Persons With Disabilities. United Nations, New York.

Wade DT and Langton-Hewer R (1987) Epidemiology of some neurological disorders with special reference to work load on the NHS. International Rehabilitation Medicine, 8, 129-137.

Wehman P, Kregel J, Scheron P, Nguyen S, Kreutzer J, Fry R et al. (1993) Critical factors associated with successful supported employment placement of patients with severe traumatic brain injury. Brain Injury 7, 31-44.

World Health Organization (1980) International Classification of Impairment, Disability and Handicap. WHO, Geneva.

(Received 24 April 1997; accepted as revised 28 April 1997) 


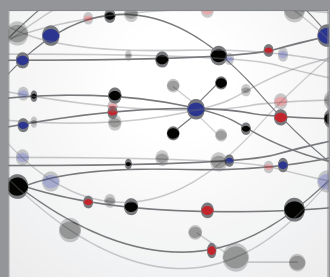

The Scientific World Journal
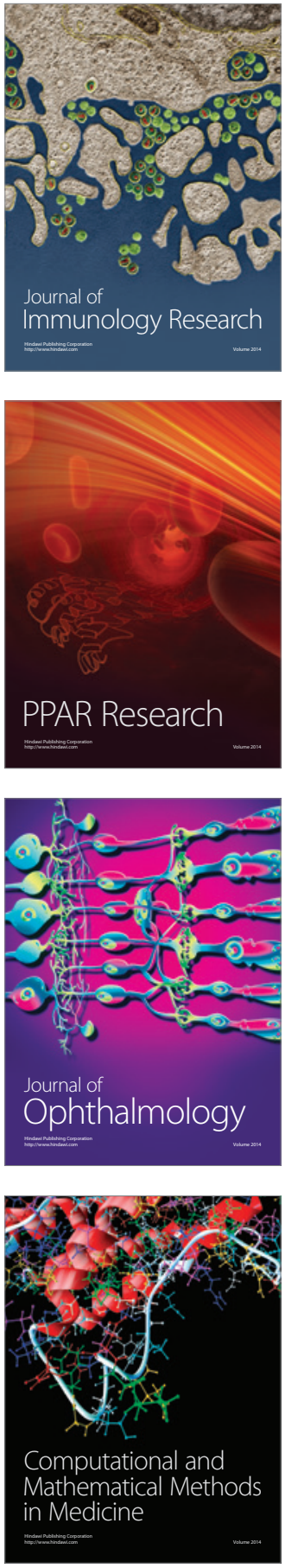

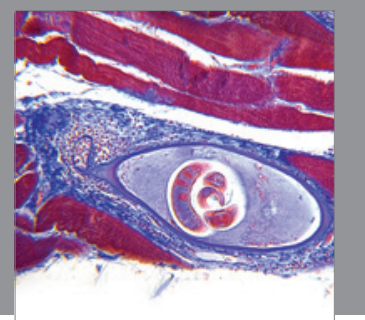

Gastroenterology

Research and Practice
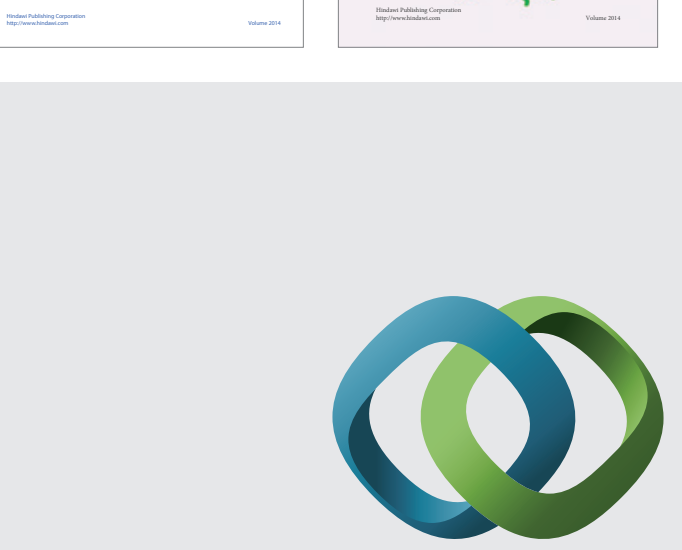

\section{Hindawi}

Submit your manuscripts at

http://www.hindawi.com
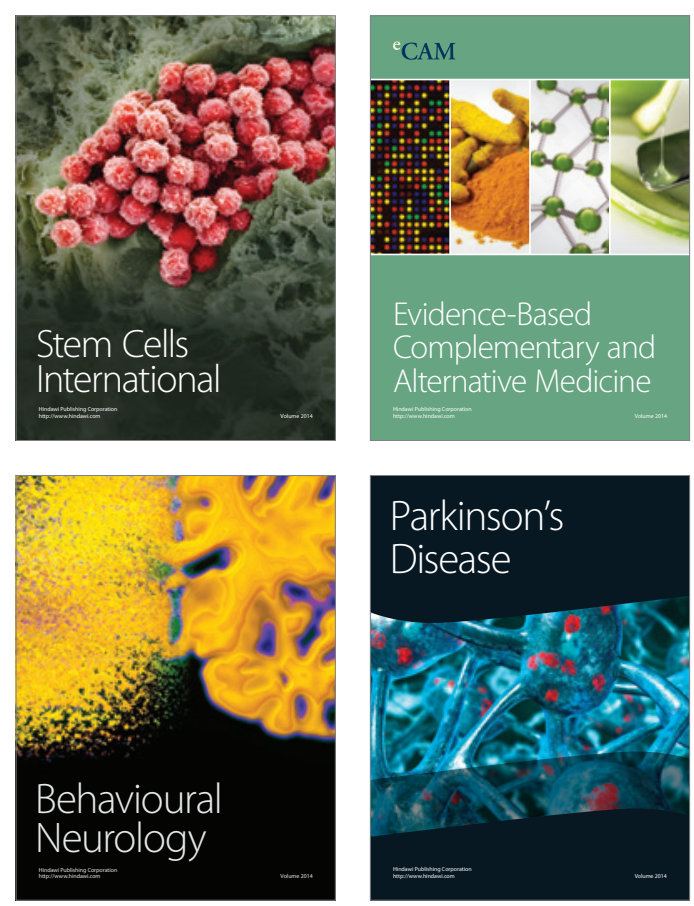

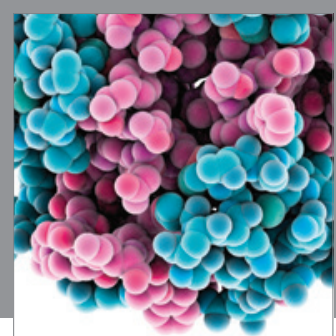

Journal of
Diabetes Research

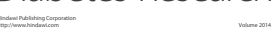

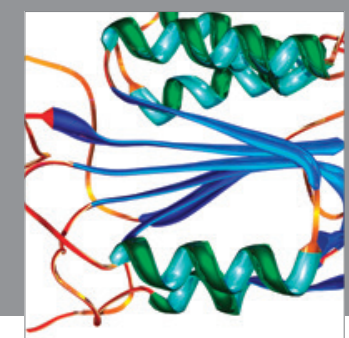

Disease Markers
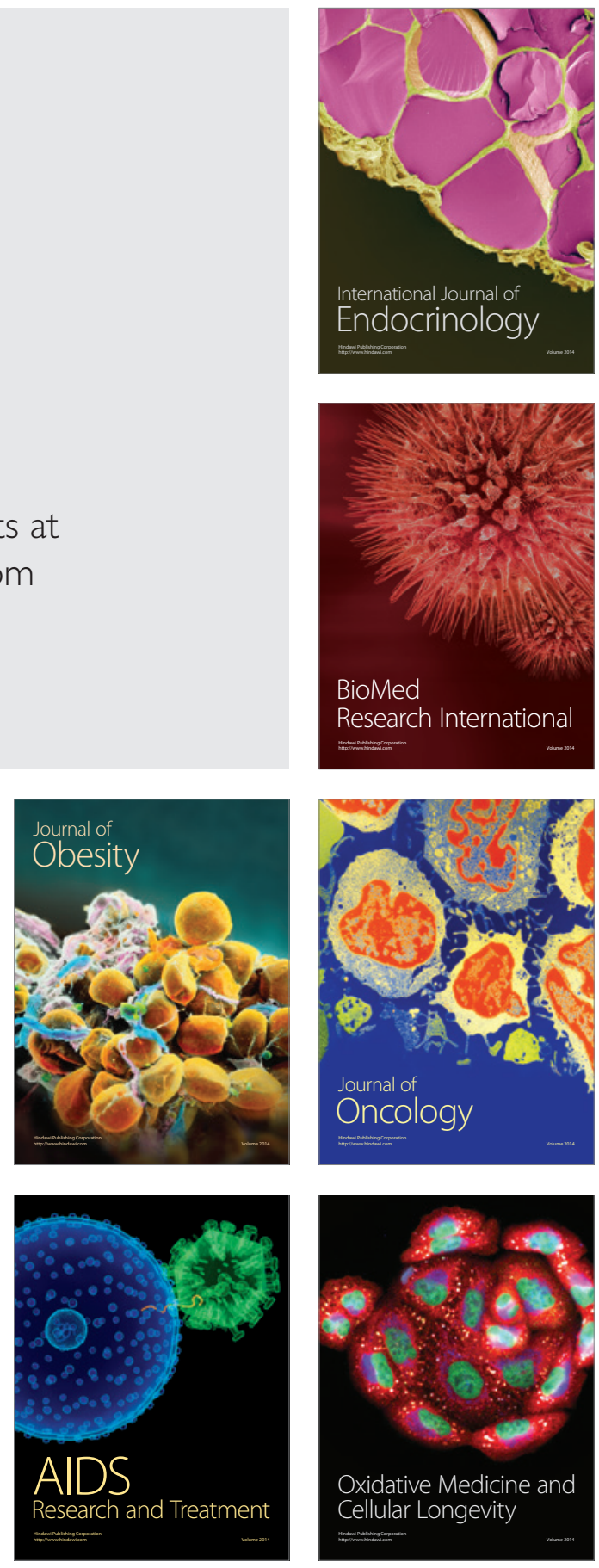